\title{
Introduction: Overcoming Barriers to the Extension of Social Protection: Lessons from the Asia Region
}

\author{
Naila Kabeer and Sarah Cook
}

\begin{abstract}
The contributions to this IDS Bulletin report on some of the findings from research undertaken under the Social Protection in Asia programme. This is a three-year policy-oriented research and network building programme, funded by the Ford Foundation and IDRC, with project partners in China, Vietnam, Indonesia, India, Pakistan and Bangladesh. The research focuses on examining interventions aimed at extending social protection to those sections of the population, the majority in many Asian countries, who are excluded from formal social security systems. It has sought to identify and address barriers to the establishment of more comprehensive social protection systems that could address such difficult-to-reach groups. This issue of the IDS Bulletin brings together some initial reflections on the findings from this research. These relate to advocacy efforts to draw attention to those groups that have been largely invisible in the social protection agenda; to the importance of civil society and grassroots mobilisation in creating access to state provision and to lessons from social protection efforts to go to scale. These reflections are intended to feed into current debates about the design of appropriate social protection schemes that effectively meet identified needs.
\end{abstract}

\section{Social protection in Asia}

Social protection is once again high on the international policy agenda as the multiple crises of the past three years have devastated the livelihoods of millions already living in or close to poverty, and increased vulnerability and uncertainty for millions more. The Social Protection in Asia (SPA) programme, under which the contributions to this IDS Bulletin have been produced, arose in similar circumstances, following the Asian financial crisis of the late 1990s.' That crisis affected many of the countries in the region which had been held up as models of market-led development. It highlighted the risks of rapid but highly unequalising growth, unaccompanied by state provision of the basic social and economic infrastructure and redistributive policies that could generate more inclusive development. The crisis provided clear lessons - that ex post safety nets were inadequate responses to generalised crisis, whether in the contexts of chronic and extensive poverty or of high inequality and exclusion (Cook, Kabeer and
Suwannarat 2003). Instead, countries seeking to compete in increasingly integrated global markets needed well-designed ex ante measures to help their populations cope with the risks associated with market liberalisation and globalisation. These lessons paved the way for a shift in thinking about social protection from piecemeal and residual interventions to a more systemic and inclusive response to risk and vulnerability.

The research presented in this IDS Bulletin feeds into current debates about the design of appropriate social protection schemes that effectively meet identified needs. It builds on an earlier phase of research that focused on the dynamics of poverty and social exclusion within the region, identifying the major problems facing groups with little coverage, and hence most likely to rely on informal safety nets (see contributions to Cook and Kabeer 2010). The research made a number of points that have since gained wider recognition. First, for the chronic poor in these

IDS Bulletin Volume 41 Number 4 July 2010 (C) 2010 The Authors. Journal compilation (c Institute of Development Studies Published by Blackwell Publishing Ltd, 9600 Garsington Road, Oxford OX4 2DQ, UK and 350 Main Street, Malden, MA 02148, USA 
countries, vulnerability to the crisis was not limited to market fluctuations but was endemic to their situation. They needed systems of social protection that could help them cope with the shocks and stresses of their normal existence. Second, well-designed social protection instruments can go beyond their immediate objective of addressing fluctuations in the income or consumption flows of vulnerable groups to achieve a wider range of impacts on livelihoods through asset-building, infrastructure and human capital development, and citizenship and social justice. These potential developmental and transformative outcomes of social protection interventions, and the conditions under which these can be achieved, have been gaining wider recognition and are examined further in these current studies.

The current phase of research focused on examining interventions aimed at extending social protection to those sections of the population, the majority in many Asian countries, who are excluded from formal social security systems. These groups include those who either work for their living in the informal economy or are dependent on others who do. They pose a major challenge for conventional models of social security. They are among the poorest sections of their country's population. They are least likely to be able to contribute to the taxes which fund the state provision of social protection. They are also least able to purchase their own forms of protection from market providers or build up the asset base that might provide them with a degree of resilience in the face of crisis. They rely largely on informal safety nets which, as the earlier East Asian crisis demonstrated, are often strained to their limits in times of generalised crisis. The SPA research agenda has sought to identify and address some of the barriers to the establishment of a more comprehensive social protection system that would address these difficult-to-reach groups. This issue of the IDS Bulletin brings together some initial reflections on the findings from this research.

\section{The life cycle of social protection interventions: an organising framework}

Social protection strategies are not designed in a vacuum nor do they emerge fully formed. They are often initiated on a piecemeal basis, the product of many different measures adopted at different points in time that are tried, tested, sometimes abandoned and occasionally institutionalised. Every intervention has its own history that is shaped by the different institutional actors, incentives and interests that prevail in the context in which it emerged. We can therefore conceptualise social protection interventions in terms of different stages of their evolution: the recognition of specific forms of vulnerability; the design and piloting of responses; the establishment of entitlements and programmes; the incorporation of lessons from experience and the scaling up of efforts and their institutionalisation. At any point in time, in any given context, we are likely to find some combination of long-established programmes, those undergoing contraction or expansion, interventions in the making, and still others that are at an early stage of ideas and advocacy.

This introduction locates the interventions discussed in the contributions to this IDS Bulletin along this evolutionary continuum. Some articles provide insights into groups and problems that continue to be neglected within social protection provisions that prevail within a particular country. A number identify potential or nascent entitlements to social protection and explore what might be needed for these to be claimed. And finally, a number of contributions focus on the implementation and scaling-up of programme interventions, addressing both technical and governance challenges. We discuss the articles in these three categories here, before drawing out implications for the wider social protection agenda.

\section{The neglected needs of excluded groups}

Three of the contributions to this IDS Bulletin are concerned with understanding the social protection needs of population groups that are frequently overlooked or marginalised within existing social protection programmes and institutions. Such groups may be vulnerable by virtue of their poverty, or due to other structural, demographic or identity-based forms of exclusion or discrimination. The three articles here are concerned, respectively, with internal migrants in China, the rural elderly (also in China) and the extreme poor in India, with a particular focus on women. As these articles illustrate, even when efforts are made to provide some form of social protection or develop interventions targeted at these groups, they often have limited impact. An inadequate understanding of their 
situation, constraints, priority needs and preferences means that interventions may be inappropriate, wasteful of resources and fail to address the underlying causes of their exclusion. At the same time, community-based or civil society initiatives do have the potential to provide innovative solutions.

Lin and Zhu provide a revealing analysis of the social protection needs of rural to urban migrants in China. They focus on housing needs as an entry point through which to explore the distinctive needs of migrants, and the mismatch between their needs and government-led efforts to extend social support to them. A significant contribution of the article is the distinction made between migration trajectories, and thus the different priorities, needs and ultimately, aspirations for final place of settlement. A minority of long-term, settled migrants may aspire to remain in their urban place of residence; the majority remain mobile, whether on a seasonal or longer-term basis, retain strong ties and obligations to support families back home, and often aspire to accumulate resources to return to the countryside to settle. Such groups clearly have very different needs, demands and preferences for social protection.

After decades of institutionalised exclusion of migrants from benefits provided to urban populations, both central and local governments in China have started taking significant steps to reform the residence permit (hukou) system and develop more inclusive policies. The dominant approach to extending social protection to migrants entails their inclusion in existing urban (often contributory) schemes such as pensions and unemployment insurance programmes. A number of studies have revealed the limitations of these approaches in cases where migrants have irregular incomes and employment, limiting the regularity of their contributions; and where the programmes have limited portability and do not meet the immediate priority needs of the migrants. Such programmes rarely meet the immediate needs of migrants and their families: pensions for example are generally a lower priority than education and healthcare.

In the case of housing, the underlying assumption behind the design of interventions is often of a one way flow of migrants with aspirations to long-term urban residence.
Interventions are developed at the municipal level, aiming to increase housing security and standards in line with urban resident housing. This may involve the integration of migrants who meet certain conditions into the existing urban housing security system and the development of improved housing for migrants in collaboration with employers. As the article argues, these policies treat migrants as though they have the same demands and aspirations as the stable urban population. Fieldwork to uncover the varied preferences and priorities points instead to other policy approaches that would better meet migrant needs in the short term, while also moving towards a more stable and integrated system. The institutional base for such a system will require strong coordination by the central state and the involvement of higher levels of government in establishing and implementing an appropriate institutional and legal framework that protects migrant rights while enabling portability of benefits.

A second population group which is of growing concern in the Asia context in general, and in China specifically, is the growing elderly population. The combination of rapid structural change, migration, demographic transition and extended life expectancy mean that the problem of an ageing population has hit China, along with many other Asian societies, while still at low levels of income and with limited welfare provisions. In the Chinese case, of particular concern are the rural elderly, a group which is for the most part excluded from any formal systems of social insurance or protection. While China has long had a social relief programme which provides minimal assistance to those termed 'Five Guarantee' (wubao) households, this only covers those elderly with no income, family, or other means of support. In the mid-1990s, the government made some effort to initiate a rural old age insurance scheme but this floundered within a decade for various reasons - in particular poor fund management - and the vast majority of the rural population remains without any pension coverage. As with migrants, lack of stable income sources also hamper regular contributions to such programmes. What alternatives exist for addressing this increasingly urgent problem?

The article by Pei and Tang examines a number of innovative community-based initiatives for 
supporting the rural elderly based on detailed field studies in three rural communities. The authors identify a range of ways in which different communities or groups of the elderly themselves, with varying degrees of financial or organisational support from local government, are addressing the issue. In the wealthier of the case study communities, collective resources, accumulated through economic development, have been used to provide guarantees of livelihood security to all village members. This model is found where a combination of strong collective leadership and a strong economic base enables both the mobilisation and equitable allocation of resources. Success in this model depends on accountable and transparent local governance that is strongly rooted in community participation.

A second case illustrates what can be achieved through self-organisation and economic activity in the absence of significant resources to distribute. In this case, the local Old People's Association played a key role in promoting economic opportunities for the elderly, generating revenues both for those who could remain economically active as well as to support those unable to work. Enabling the elderly to make a substantial economic contribution to households and the community in turn improves the support and care received within their households, and in some cases, improves intergenerational relationships. The study points to the need to view rural elderly support not only in terms of relief and assistance, or income maintenance, but also in terms of the contributions the elderly make to their communities. The third village is perhaps most unusual in that a group of elderly from a poor village, acting independently, reclaimed land and set up a self-sustaining community apart from the village and their families. They received limited government or other organisational support. Like the second case, however, it illustrates the potential for continued economic and productive activity by the elderly. Together, these cases highlight the potential for local government, community and self-help activities to support the elderly in ways which also benefit the local economy and community. While the longer-term national aims of a basic social pension will have a significant impact on the livelihoods of the elderly and their families particularly in poor regions, these should be combined with the encouragement of local initiatives that can better meet the needs both of the elderly and their communities.

The final article in this category, by Huda, examines the obstacles to reaching the extreme poor in South Asia, and particularly women - a group that is systematically excluded from mainstream government efforts to address poverty. They have also been marginalised from NGO efforts, including microfinance programmes. There are various factors at play. Women generally tend to have fewer assets at their disposal and fewer opportunities relative to men, even within the same household. They face constraints on the basis of their gender, including social restrictions on the kind of work available to them, child care responsibilities and the prejudice of employers, landlords and moneylenders. Women who, in the absence of male breadwinners, must support themselves, are likely to predominate among the poorest sections of the poor in South Asia.

Such experience suggests that the extreme poor are unlikely to benefit from the same set of programmes as the moderately poor and a variety of interventions have been designed to address their specific needs and constraints. One genre of interventions, referred to as Targeting the Ultra Poor (TUP), was pioneered by the Bangladesh Rural Advancement Committee (BRAC) after a series of evaluations had shown that it was failing to reach the extreme poor. In contrast to the various types of cash transfer programmes currently promoted by the official donor community (see, e.g. the article on Indonesia, this IDS Bulletin), the TUP programmes provide a package of inputs and support which are intended to assist ultra-poor women not only to meet their immediate needs but also to move from dependence on social transfers to sustainable livelihoods.

The TUP approach is now being piloted in a number of other countries in collaboration with both NGOs and government. Huda's article provides insights from the first stage of piloting in India by one of the country's largest microfinance organisations. She notes the importance of keeping the design features as simple as possible in order to facilitate the scaling-up of the programme, as well as the intensive investment in 'handholding' support necessary to provide a highly vulnerable group with the self-confidence 
to take on new livelihood challenges. One of the questions raised by Huda, and one we return to later, is to what extent this combination of standardisation and dedication can be replicated by the state, with its penchant for top-down delivery but capacity to go to scale, and to what extent there is a role for development NGOs to address these very specific needs and constraints.

\section{Establishing entitlements, making claims}

Housing, and particularly secure tenure rights, was raised as a very basic need in the lives of the poor in the first phase of the research and it features again in a number of studies in the current phase. Earlier studies illustrated the multiple roles of housing as shelter, a site of production and a place of protection (Cook and Kabeer 2010). These multiple features are particularly critical for women who are more likely to be engaged in home-based work, and for whom housing (or land) rights provide a critical asset to enhance their bargaining power in relation to family members or the wider society. In highly urbanised environments, such as Hong Kong and Singapore, housing policies have formed an essential basis of social security provision. As the articles in this IDS Bulletin argue, secure rights to housing also underpin the ability to claim other entitlements. The lack of a stable residence or address is often a barrier to accessing other benefits, and reduces the likelihood of being reached by government or NGO programmes.

Housing tenure rights are closely tied to questions of land ownership. Land redistribution played an important role in providing a minimum degree of security to rural populations in countries such as China and S. Korea, but land reform efforts in South Asia have persistently foundered in the face of resistance from powerful landed elites. As processes of industrialisation and increasing inequalities of wealth inflate the price of land, the urban poor in particular are priced out of housing markets and pushed to marginal settlements, with scant infrastructure and often far from economic livelihood opportunities. In contexts where market access is unaffordable, and where any recognised rights to land or housing have proven politically impossible to implement, what alternative mechanisms exist for extending some degree of residential security to poor people in ways that recognise its role as a critical dimension of social protection policy?
Two contributions from South Asia, which illustrate both extreme market exclusion and the political inability to provide guarantees of basic rights to housing, examine different options for extending tenure security, while also exploring the ways in which residential security can underpin the ability to access and claim other entitlements. As Gazdar and Mallah point out based on research in Pakistan, the provision of title or security of tenure over residential land appears to have had a greater, but less welldocumented, number of beneficiaries than agrarian land reform. The article explores the extent to which such schemes benefited some of the poorest among the intended beneficiaries, in particular examining the SGAHS ${ }^{2}$ (Sindh village development and housing scheme), which was launched in 1987. This programme allowed village inhabitants to apply for the regularisation of their tenure rights, considered to be a necessary condition for the physical development of the village. Official data suggest that over 11,000 villages have been regularised, and individual leases have been allotted to over 700,000 beneficiary households, benefiting over 4 million people. Examining the history of this scheme, Gazdar and Mallah reveal that it was implemented in a context where access to homestead and other land was governed by a complex cluster of individual property rights, customary rights as well as claims established through the use of force by more powerful sections of the village hierarchy. Social marginalisation in the context of Pakistan, as in the rest of South Asia, was generally closely linked to differential local rights and privileges relating to homesteads and other residential and social uses of land.

From this perspective, the scheme had the potential to subvert some of the customary privileges which had de facto benefited the rich and powerful at the expense of the marginalised. However, it required the capacity for collective mobilisation. They found that previously marginalised families and groups had been able to realise the subversive potential of the scheme; the scheme had thus acted as a catalyst for effective mobilisation by these groups and was a factor in their upwardly mobile trajectory. However, there were some glaring exclusions: women who had no property rights within patriarchal family systems, and extremely marginalised groups who were simply too weak 
to articulate the demand for residential security. Such groups are more likely to benefit from forms of social protection that are not predicated on the capacity to mobilise around their claims. The new cash transfer scheme currently being rolled out in Pakistan offers an example of this.

The article by Mahadevia focuses on the challenge of residential security in the urban context. It too points to mechanisms that fall short of recognising housing as a de jure statutory right but that nevertheless afford a sufficient degree of residential security to help the urban poor address some of the other deficits in their lives. She distinguishes between insecurity of tenure, on the one hand, and weak and strong de facto security. De facto security is achieved by low income households through a variety of means, based on their own resourcefulness, through the efforts of NGOs and through the policies of the municipal government. She is able to show how, in the absence of any policy by the state government to address the residential needs of the urban poor, incremental improvements in their security of tenure over time has provided the basis for access to other social protection entitlements as well as for improvements in the quality of life. However, the pace of change is slow. While number of years of residence in the city does lead to some improvements in some entitlements, her analysis suggests that it may be at least 20 years before these improvements become significant. This, coupled with the absence of improvement in access to other entitlements, suggests that the pace of improvements in the lives of the urban poor could be accelerated by state support or community-based initiatives.

\section{Operationalising and scaling-up social protection interventions}

A third set of articles deals with specific programmes that are currently being implemented by governments. The challenges involve improving design, addressing governance issues, reintegrating lessons from experience or initial evaluations, and expanding coverage to reach intended beneficiaries.

Two of these contributions deal with the National Rural Employment Guarantee Scheme (NREGS) in India, now re-named the Mahatma Gandhi Rural Employment Guarantee Scheme. In one sense, this scheme represents the culmination of strong pressure from a coalition of civil society activists to address the failure of economic growth in India over the past decade, to translate into commensurate rates of poverty reduction and employment generation. It also represents the culmination of lessons learnt from previous government experiences with public works programmes. In another sense, however, it is the start of a new learning process as the Indian government struggles to implement the world's largest experiment in a rights-based approach to employment generation for the rural poor.

The two articles on the NREGS deal with somewhat different aspects of the programme. The article by Reddy, Tankha, Upendranadh and Sharma examines the different stages of the process through which the programme is operationalised. These stages are of particular significance because they reflect attempts to address previous governance failures of public work schemes, as well as to give substance to the rights-based approach that underpins the current programme. In particular, a number of steps explicitly attempt to deal with problems of corruption, with ensuring transparency of process, with linking infrastructure development with local governance structures and with creating assets for poor and marginalised groups. The article compares how the states of Andhra Pradesh, Rajasthan and Bihar have performed on these different process indicators, as well as some of the factors that explain their varying performance. Indicators include outreach to extremely poor and socially marginalised groups along with the extent to which provisions made at different stages of the implementation process have been observed in practice. They find that Bihar, a state that has been held back for several decades by the poor quality of its governance, continues to perform badly on most of the process indicators. Both Andhra Pradesh and Rajasthan, on the other hand, perform reasonably well. These variations in performance can be traced to a number of key factors.

One was the ability of relevant government functionaries to discharge their obligations: this included their technical expertise, their existing workloads, incentive structures and work facilities. A second factor was the extent to which village committees were active and functioning, since these planned local, needsbased public works portfolios to be undertaken 
under the programme. A third was the willingness of state governments to carry out innovations to ensure the successful implantation of a centrally designed national programme. The use of biometric smart cards to pay workers' wages in Andhra Pradesh was found to both reduce transaction costs and promote transparency in the payment process. A final and critical factor was the presence of active associations and groups, formed by NGOs as well as government, willing to collaborate in the implementation process as well as to hold officials accountable. This was a major factor that differentiated the experience in Rajasthan, Andhra Pradesh and Kerala (covered in the article by Sudarshan, Bhattacharya and Fernandez) from that in Bihar.

The article by Sudarshan et al. takes a different set of findings as their point of departure. They are interested in finding out the factors behind the very varying rates of female participation in the NREGS in the 26 states of India. Selecting Rajasthan and Kerala as examples of states with high rates of female participation and Himachal as an example of a state with very low female participation, they explore in greater detail what explains these patterns. Their findings encompass the nature of local labour markets, the presence of active women's groups and level of state commitment. Thus in Kerala, where wages paid on the NREGS exceed that which women are able to earn through wage labour in local agriculture, though fall short of what men are able to earn, the programme has succeeded in drawing in large numbers of women, many of whom were not working previously. By contrast, in Himachal Pradesh, most women were involved in agricultural work on their own fields and in the difficult tasks of collecting water and fuel in mountainous areas. Few were available for wage work on NREGS.

In addition, Kerala has undergone probably the most genuine decentralisation process of all the states in India and the government has been active in promoting self-help groups of women who took responsibility for managing the programme in many villages. Rajasthan has an active and engaged civil society and was one of the states leading the Right to Information movement. Sudarshan et al. note the presence of an NGO that had facilitated the organisation of the informal youth groups who kept up scrutiny of the work of local government and appeared to have improved the functioning of formal institutional structures. While there were informal women's groups in Himachal, these had restricted their activities to women's traditional roles and not sought to either disseminate information about the programme or audit its implementation.

Three other projects fall into this category of studies which attempt to evaluate and draw lessons from existing interventions and programmes. These include an analysis of a new conditional cash transfer programme in Indonesia (the Program Keluarga Harapan, or $\mathrm{PKH}$ ), an evaluation of China's New Cooperative Medical Scheme (NCMS), and finally a study not of a specific programme, but rather of the system through which social protection is provided in the event of disaster, drawing on research undertaken in the aftermath of China's Wenchuan earthquake.

In 2007 the government of Indonesia introduced a conditional cash transfer (CCT) programme the $\mathrm{PKH}$ - aimed at providing cash transfers to the chronically poor to help them access basic education and health care, with the longer term objective of breaking the intergenerational transmission of poverty. The programme was introduced in part to compensate for the ending of subsidy programmes, introduced following the Asian financial crisis, but which had become fiscally unsustainable in the light of fuel and food price rises. CCT programmes have become the social protection intervention of choice by a large number of governments and donors around the world, based in particular on their experience and apparent success in Latin America. Their rapid scaling-up and replication has occurred at times without appropriate adaptation to local conditions and with insufficient evaluation of their wider impacts. Research undertaken by SMERU aims to provide an in-depth evaluation of the programme along a number of dimensions, focusing in particular on the gender impacts, the implications for intra-household relations and allocation, and the wider economic and community impacts of the resource transfers.

The article by Syukri, Arif, Rosfadhila and Isdijoso focuses on one particular aspect of the PKH, namely how the cash transfer is used by 
households and the extent to which this is compatible with the design and objectives of the programme. Based on in-depth fieldwork in four villages, the study identifies variations in resource use across rural and urban villages with different economic structures and resources. A significant difference arises between the poor in villages with land, who rely largely on subsistence agriculture supplemented by some wage labour; and those without land, who rely on irregular agricultural or non-agricultural wage employment.

The design of the programme did not explicitly stipulate the use of the cash. Behavioural conditionalities focused on the use of health and education facilities including pre- and postnatal check-ups, child immunisation and school attendance. Recipients were poor households with children of a certain age range. Field advisors were critical in helping households make decisions about the best use of the transfers, and appeared to provide flexibility to assist households in overcoming their specific livelihood constraints. Cash transfers were thus used not only to meet the direct costs related to programme conditionalities, such as transport to facilities or school materials; nor were they only used for the children within the targeted age range.

Households also used cash for consumption purposes, and occasionally for investment; and they spent resources on other children not explicitly targeted by the programme. While it is possible to narrowly interpret this as not full compliance with the programme, it appears that the choices were in line with the broad objectives: expenditures on consumption are essential for achieving improved nutritional, health and education outcomes; where investments are possible, they may generate future income thus reducing poverty; and enabling older (not targeted) siblings also to remain in school again contributes to the overall goals.

Despite some suggestions that the use of funds indicates a lack of rigorous compliance with programme conditions, and that tighter conditionalities or regulations would improve implementation, in fact it appears that the goals of the programme are being met while giving households the flexibility to make decisions most appropriate to their specific circumstances. Restricting the use of funds would certainly entail higher administrative costs, while possibly undermining the broader, long-term poverty reduction objectives. The challenge in such circumstances, where programmes are being rolled out in fiscally constrained environments, is to develop appropriate evaluation criteria and mechanisms that recognise the wider benefits, to the households and communities, of more flexible arrangements.

In China, one of the major new social protection initiatives of the past decade has been the establishment of a New Cooperative Medical Scheme (NCMS). Three decades of reforms and market liberalisation resulted in basic services, including health and education, being commercialised. The results were rising costs, neglect of investment particularly in remote or poor regions, and increasing gaps in access and quality between different groups, based on location and income. The health achievements of the collective era were being undermined, and even reversed. Increasing evidence pointed to catastrophic health expenditures as the leading cause of poverty, while ill-health was also undermining the ability of households to move out of poverty. The NCMS thus represents a renewed attempt by the Chinese government to extend medical coverage to the rural population in recognition of the impoverishing effects of illhealth.

The article by Zhang and Yi provides an evaluation of key dimensions of this programme using two rounds of data from a nationally representative household sample survey undertaken in 2005 and 2008. The key elements of the programme discussed in this article concern participation and coverage, and effectiveness in reducing the incidence of catastrophic medical expenditures. The findings show that coverage has greatly expanded, and there appears to be growing understanding and trust in the scheme. Transparency of funding arrangements, clarity of reimbursement procedures, and mechanisms such as individual accounts, have all helped to raise confidence in the programme. The rural population is more likely to seek medical care, and average reimbursement rates have increased. However, the NCMS has not succeeded in its main goal of addressing the problems of catastrophic medical payments. Here, the fundamental problem is insufficient funding, but also appears closely tied to the structure of medical provision and reimbursement rates. To incentivise the use of 
lower cost (and quality) township clinics, reimbursement rates are high at these lower level facilities. Thus, patients with more serious illnesses and requiring more sophisticated treatment face both higher costs and lower rates of reimbursement. Furthermore, as funds (and thus risks) are pooled at county levels, there is relatively limited scope for risk-sharing or redistribution through the financing system.

As the article concludes, to ensure that the system becomes effective in addressing the health needs of the rural population, additional funding will be needed, while coordination, financing and management, and thus riskpooling, will need to take place at higher levels of the administration. In addition, greater redistribution will need to be built into the system to ensure adequate access to quality facilities by the poor. While the expansion of the scheme has been impressive - and this may in part be attributed to the flexibility among local governments to develop programmes in keeping with local circumstances - there will now need to be a balance between local flexibility and responsiveness in design and implementation, and the need for a more uniform, integrated and redistributive system.

A final article in this group looks not at a specific social protection scheme, but rather at the system that delivers social protection, and the institutional arrangements that make such systems resilient and responsive in the event of major stress such as a natural disaster. The article by Hu, Salazar, Q. Zhang, Lu and X. Zhang examines how the social protection system responded to the needs of victims of the Wenchuan earthquake of May 2008. Measured by loss of life and other damage, this was the most serious disaster in the 60-year history of the People's Republic of China, leaving almost 90,000 people dead or missing; 375,000 injured, and $13 \mathrm{mn}$ homeless. Such devastation would overwhelm the capacity of most systems.

The immediate response was rapid and effective, drawing on national and international resources. China's disaster relief system is well-established, with clear guidelines as to which level of government is responsible depending on the scale and complexity of the disaster; it also entails twinning arrangements between provinces or other localities to provide various types of assistance. A range of channels of support can thus be mobilised at short notice. Nonetheless, the rapid organisation, coordination and appropriate delivery to those affected relies also on local infrastructure, including the institutional arrangements of government down to the village and household level. While there is extensive literature on various aspects of disaster relief and recovery, few studies have examined the factors that make these systems resilient and responsive. The research presented here took an innovative approach, starting with involvement in the immediate aftermath of the disaster, to assess both the needs of victims and the support received, as well as the situation of local officials and others involved in delivery of relief and social protection.

The article illustrates the extreme strains on the system and the cracks that emerge over time. The intensity of the immediate response, and the demands placed on individuals who are themselves often victims (through loss of family members or housing), can be maintained for a short period. By the time immediate relief turns to longer-term reconstruction, estimated to be around six months, this toll becomes particularly acute, seen for example in higher rates of illness, smoking and alcohol consumption among officials. These initial findings from the study, point towards important issues for further investigation, in order to understand the points at which weakened institutional resilience and capacity may result in systemic failure, and what needs to be done to strengthen systems both $e x$ ante and following a disaster. Given that natural disasters are a major source of generalised vulnerability across the world, the study has important implications concerning the need for and nature of resilient social protection systems.

\section{The broader social protection agenda:} considerations for policy and practice

Each of the articles discussed above offers lessons for making social protection strategies more systematic and inclusive. In addition, collectively they provide insights into a number of general themes that are important for the wider social protection agenda.

\subsection{The role of multiple institutions and actors}

It is evident from the contributions to this $I D S$ Bulletin that different sets of actors are active in different contexts. These include: national, local and municipal governments, non-government 
development organisations, community-based and informal associations, microfinance organisations, international donors and private philanthropic foundations. While often not explicitly identified, the default option for the poor, in the absence of other actors, is their own informal networks.

Private market providers, on the other hand, are remarkable for their absence. Vulnerable groups within the informal economy are by definition excluded from formal social security arrangements: they lack access to private insurance mechanisms for security. Where they do rely on the market for basic services (transport, health, education, housing), they can access only irregular, unregulated and low quality provision which does not meet basic needs, and which in fact (as the case of commercialised health care in China shows), may push them deeper into poverty.

Several articles indicate that, while specific actors may play different roles in providing social protection, effective outcomes frequently rely on the relationship between these actors. Central and local governments can play complementary roles (as in NREGS and NGMS); local government, community and civil society actors can be mutually supportive actors; the state may provide the framework within which claims to entitlements can be made (as in the cases of tenure security); and while civil society and community-based associations may mobilise to fill gaps that fall outside the remit of government, these functions cannot be performed as effectively where governments fail to deliver.

The critical choice is not state versus market; nor is it about whether civil society or government is best placed to deliver social protection.

Delivering on broad goals of social and economic security requires the involvement of all actors in synergistic relationships. To move towards a comprehensive and inclusive system, however, requires a strong role for the state in setting policy frameworks, in regulating (particularly private) providers, and in ensuring adequate financing, redistribution and risk-sharing, without which the poor will remain marginalised.

\subsection{Information, accountability and participation}

A related aspect concerns the relationship between intended beneficiaries and the programme, particularly front-line providers.
Expanding coverage in schemes like NGMS and NREGS involves establishing trust in the programme through providing information, being responsive to needs, and ensuring transparency particularly in the allocation of funds. As the study of the earthquake relief showed, perceptions of fairness in allocation may be more important than actual outcomes. The governance arrangements for programmes are critical to their success: even with local community-based initiatives, as in the case study of rural elderly care in China, strong but accountable community or village leadership was fundamental.

In programmes that address the extreme or chronically poor, such as the TUP pilot in India and $\mathrm{PKH}$ in Indonesia, local fieldworkers play a critical role not only in providing information but in working with the poor, assisting in decisionmaking over the use of resources, and in empowering the excluded to participate in programmes and processes. In such cases, local groups, such as development NGOs with roots in the community, may be best placed to play this role, suggesting a partnership model combining the capacity of government to scale-up and coordinate programmes and the capacity of NGOs to adapt to local needs.

\subsection{Responding to diverse needs}

Those excluded from formal social protection are not a homogenous group and are unlikely to benefit from uniformity of provision. The distinction Huda makes between the extreme and moderate poor, speaks to the tensions between standardisation to achieve scale of outreach and responsiveness to ensure outreach to the very poor. In China, migrants are shown to be distinct groups in terms of their needs and priorities for social protection, while public works schemes such as NREGS cannot be effective in meeting the needs of certain groups of the poor (e.g. those in remote locations, the elderly and disabled, or pregnant women). Programmes can be better designed to meet diverse needs, but a range of different types of intervention will be necessary to ensure inclusive coverage groups.

\subsection{Financing social protection}

Many of the formal programmes discussed in this IDS Bulletin are social transfer programmes of various kinds, based not on financial contributions of the beneficiaries, but funded through resources mobilised in other ways. 
These include national or local taxes, contributions from international donors and philanthropic foundations, funds raised through microfinance operations or resources generated within the community. A major concern in the social protection literature is the affordability of programmes, and their sustainability, particularly when initiated by international donors. Long-term sustainable social protection systems must, in the final analysis, rely principally on domestic resource mobilisation, while effective social protection requires a strong element of redistribution.

Resource allocation to such programmes is often opposed by elites who oppose redistribution for what are considered 'welfare' programmes that promote dependency, while making no contribution to economic growth. Recent literature, including some of the articles here, point to the ways in which social protection programmes can have wider developmental impacts that offset some of the resources used to

\section{Notes}

1 The initial phase of the project was supported by the Ford Foundation through its offices in Asia. A second phase from 2007 to 2010, of which some initial findings are presented here, is supported by the Ford Foundation and IDRC.

\section{References}

Cook, S. and Kabeer, N. (2010) From Deficits to Trajectories: Rethinking Social Protection as Development Policy in Asia, New Delhi: Routledge finance them. These include investments in human capital leading to a more healthy, skilled and productive workforce; the creation of local infrastructure; increasing incomes that generate local economy effects through increased market activity; the relaxation of constraints which prevent labour force participation (particularly for women), or raise productivity in household production, and a reduction in coping strategies that undermine productivity and may lead to distress migration.

These developmental impacts have not yet been studied in any systematic way. What the various findings from a range of studies suggest is however, that far from promoting the dependency of the poor on welfare handouts, well-designed social protection interventions can provide the opportunity ladders that they need to climb their way out of poverty, to participate in social and political life, and to contribute to wider processes of development and inclusive economic growth.

2 SGAHS: Sindh Goth-Abad (Housing Scheme) Act, 1987.

Cook, S.; Kabeer, N. and Suwannarat, G. (2003) Social Protection in Asia, New Delhi: Har-Anand Press 